\title{
Sistema de Gestión Universitaria de Calidad
}

\author{
Dr. Mario IBÁÑ̃E MACHICAO
}

\section{INTRODUCCIÓN}

Estamos en la era de una sociedad del conocimiento globalizado y, el Perú no puede aislarse ni ser ajena a esta realidad; con mucha más razón la universidad porque es el eje principal, la esencia cultural de una sociedad en particular, en este caso nuestra sociedad peruana.

El Perú tiene desafíos y cada vez más nuevos desafíos para ser una sociedad encausada en la modernidad, la innovación, la creatividad y el desarrollo tecnológico, cuyos factores son o tienen que ser PRODUCTO NATO de la universidad, a través de la investigación de sus estudiantes, profesores y egresados.

La universidad, en el cumplimiento de sus fines, está obligada a demostrar que, efectivamente su razón de ser, es la de investigar, cuyos resultados respondan a las necesidades prioritarias de la sociedad peruana, especialmente en el campo del desarrollo tecnológico, la creatividad y la innovación que son los carencias existentes en nuestro país para responder frente a los inmensos factores negativos que se nos presentan y son obstáculos para un desarrollo socio económico del pueblo peruano.

\section{Sistema de Gestión Universitaria de Calidad (SISGUC):}

EL Sistema de Gestión Universitaria de Calidad es una herramienta administrativa de mejoramiento continuo, basado en la interrelación de todos los elementos constitutivos de la universidad, en sus procesos operativos académico administrativos, para lograr los objetivos de la universidad, dentro de su visión, misión y, de su finalidad de: formación, investigación y proyección social, todas, para satisfacer las necesidades de la sociedad peruana.

\section{Objetivo}

$\checkmark$ El SISGUC tiene el objetivo de crear, mantener y mejorar, cíclicamente, el nivel de formación universitaria que brinde satisfacción en los usuarios (estudiantes, padres de familia, el mundo empresarial o la sociedad en su conjunto). 
Aceptar y viabilizar la necesidad de una formación de calidad, que en estos tiempos de competitividad globalizada, el usuario demanda un servicio, cada vez, de mejor calidad que satisfaga sus necesidades y expectativas.

Ostentar a la calificación de universidad de calidad, mediante una autoevaluación objetiva, la misma que sirva de base para la acreditación académica nacional e internacional para luego seguir con el mejoramiento continuo y sostenido.

El Sistema de Gestión Universitaria de Calidad, permite crear una Cadena de Valor:

El Sistema de Gestión Universitaria de Calidad, exige y garantiza:

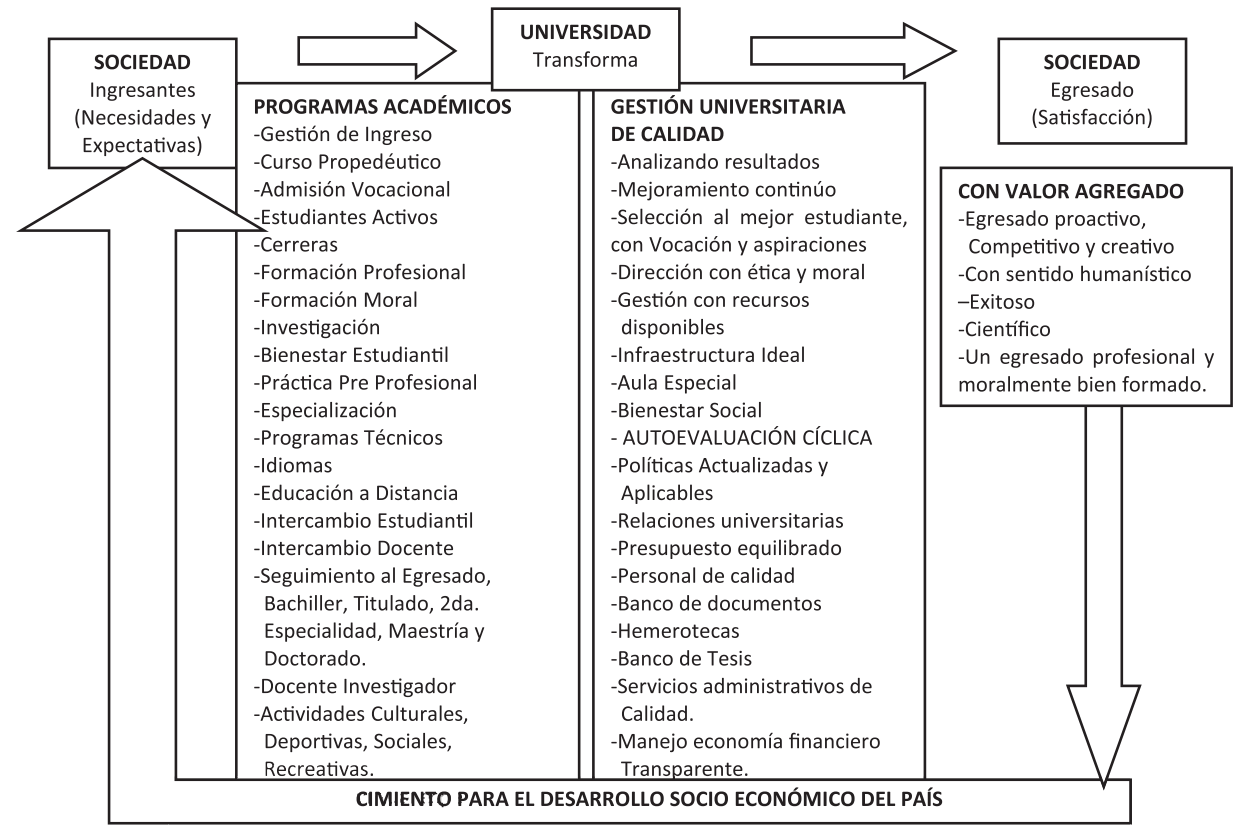

\section{Gestión Universitaria de Calidad}

Toda acción o decisión en una gestión universitaria de calidad debe darse, previa consulta a los tres aspectos básicos de dirección de una organización social:
a. Aspecto Humano (Somos seres humanos)
b. Aspecto Técnico (Disponibilidad recursos)
c. Aspecto Legal (Dentro de los límites de las normas)

Si no hay recursos disponibles, no tiene sentido una decisión. (Es errada) Igualmente, un plan de acción sin presupuesto de gastos, no logra metas u objetivos. (Es imposible) 
Dimensiones, Factores, Criterios, Indicadores y Estándares de Acreditación de la Universidad Peruana (Diseño CONEAU)

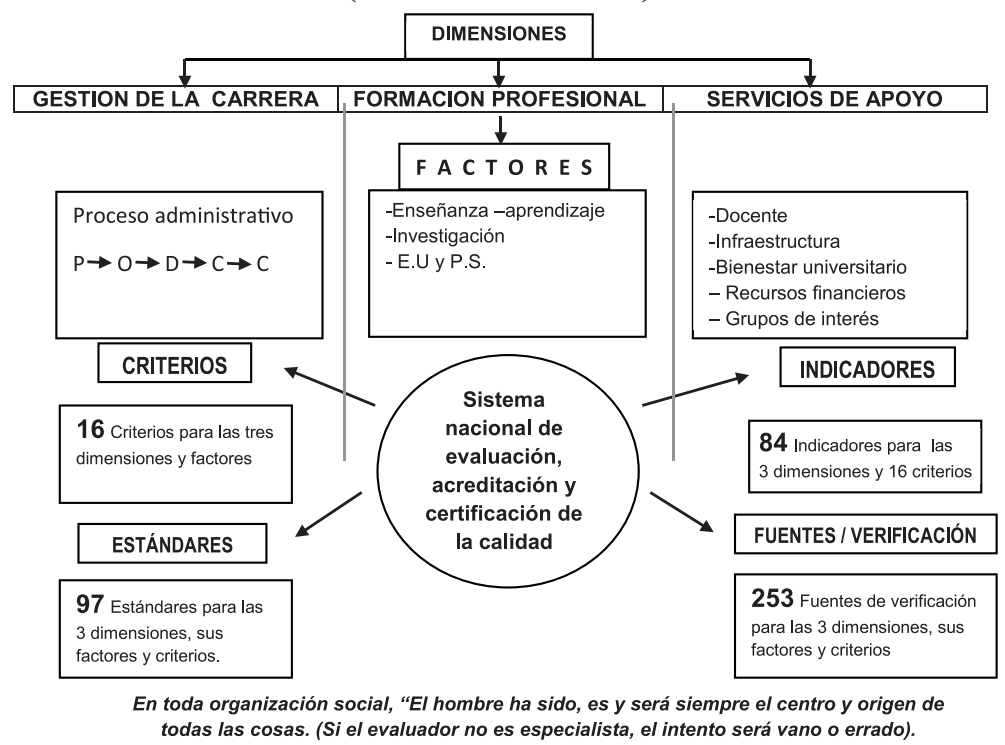

Un Sistema de Gestión Universitaria de Calidad, se inicia:

Fundamentalmente, se inicia en sus Recursos Humanos:

$\checkmark$ Alta dirección - Calidad en sus decisiones: Técnico, económico y oportuno.

$\checkmark$ Decanos - Planificador-operador de mando medio, especialista racional en sus decisiones y en la gestión universitaria.

$\checkmark$ Directores - Especialista, con supervisión de calidad en la gestión universitaria de su Escuela académico profesional (carrera).

$\checkmark$ Docentes - Con grado de Doctor, especialista en la asignatura identificado con su carrera. "No se puede enseñar lo que no se ha practicado"

$\checkmark$ No docentes - Cualidades personales para prestar servicio de calidad al estudiante, padre de familia y visitantes.

Estudiantes - Seleccionado por haber sido estudiante sobresaliente de secundaria $\mathrm{y}$, por tener vocación para ser estudiante universitario de calidad en su carrera.

Egresado - Participativo, con críticas, sugerencias, opiniones y recomendaciones para su Aula Mater.

"Un cerebro que no es explotado satisfactoriamente, con el tiempo se deteriora y, generalmente crea problemas, por su sensibilidad humana".

Un Sistema de gestión universitaria de calidad, en la DOCENCIA, exige:

$\checkmark$ Mayor identidad del docente con su universidad.

$\checkmark$ Mayor competitividad interna - externa del docente. 
$\checkmark$ Mayor conciencia de responsabilidad universitaria docente.

$\checkmark$ Estabilidad emocional, frente a la situación socio-económica del país y de la universidad.

$\checkmark$ Incentivos efectivos por los méritos alcanzados.

$\checkmark$ Rejuvenecimiento docente, cíclico, con una edad promedio.

$\checkmark$ Investigación docente, efectiva, en su especialidad.

$\checkmark$ Producción intelectual del docente, obligatoria y cíclicamente, probado.

$\checkmark$ Subordinación del interés personal al interés general de la universidad, en sus decisiones.

$\checkmark$ Auto actualización académica, permanente.

Un Sistema de Gestión Universitaria de Calidad, en el ESTUDIANTE, exige:

$\checkmark$ Examen selectivo de admisión, vocacional.

$\checkmark$ Menor número de alumnos por asignatura - profesor.

$\checkmark$ Mayor número de horas de investigación universitaria del estudiante.

$\checkmark$ Eliminación de la titulación por "Curso de titulación".

$\checkmark$ Titulación mediante 2 semestres de seminario de tesis, objetivo, con sustentación obligatoria, al final del 10mo ciclo.

$\checkmark$ Designar un profesor tutor, por cursos afines, para motivar y actualizar al estudiante y evitar la deserción.

$\checkmark$ Establecer turnos de estudios: Mañana - Tarde, a fin de facilitar el estudio universitario para los estudiantes que trabajan, sólo a partir del 6to ciclo.

$\checkmark$ Introducir concurso de aptitudes desde el 3er. Ciclo, con incentivos ejemplares para el Estudiante destacado, por cada carrera.

$\checkmark$ Excelencia académica con docentes especialistas con experiencia profesional ejercida en su materia, incentivado.

$\checkmark$ Investigación docente efectiva, en su especialidad, incentivada.

$\checkmark$ Producción intelectual del docente, obligatorio, cíclico, cada cuatro años.

ELRECURSO HUMANO DE LA UNIVERSIDAD ES COMPLETAMENTE HETEROGÉNEO, EN CUANTO A:

$\begin{array}{lll}\text {. Raza } & \text {. Nacionalidad } & \text {. Nivel educativo } \\ \text {. Edad } & \text {. Estado civil } & \text {. Condición social } \\ \text {. Necesidades humanas } & \text {. Personalidad } & \text {. Aspiraciones } \\ \text {. Antigüedad } & \text {. Dedicación } & \text {. Profesión }\end{array}$

. Etc.

Una gestión universitaria de calidad, desde el punto de vista subjetivo, requiere de transformar el grupo humano heterogéneo en un grupo humano homogéneo; es decir, crear una cultura organizacional, donde, "el hombre ha sido, es y será siempre el centro y origen de todas las cosas en la Universidad". Esto exige: respeto, cordialidad, amabilidad, compañerismo, cordialidad, lealtad, calidad humana, armonía, desprendimiento, para crear una armonía laboral. 
Un Sistema de Gestión Universitaria de Calidad, exige: Relaciones Humanas, Alturada, a Nivel Universitario:

En las Relaciones:

- Inter funcionales

- Inter personales

En el trato Humano:

- Alta dirección - Mando medio

- Mando Medio - Jefe.

- Jefe - Trabajadores (No docente).

- Docente - Estudiante.

- Entre Docentes.

- Entre Trabajadores.

EL EJE PRINCIPAL O PUNTO DE EQUILIBRO DE UN "SISGUC" ESTÁ CENTRADO EN:

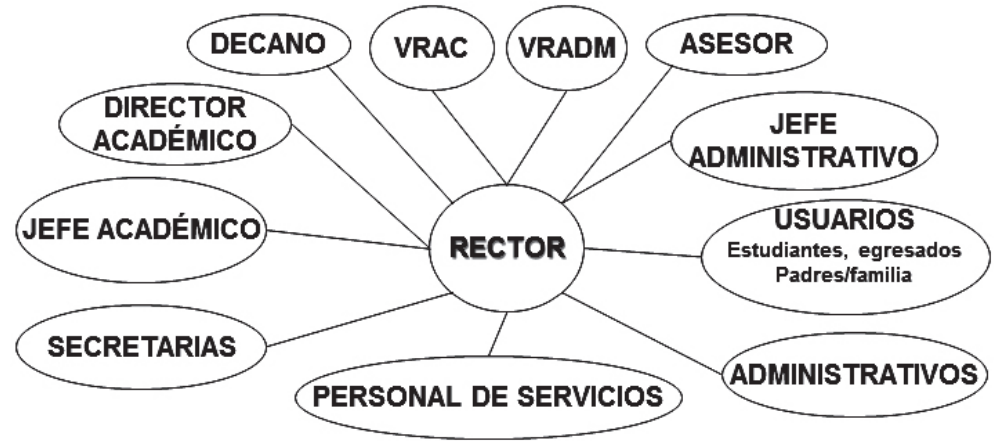

El Sistema de Gestión Universitaria de Calidad, permitirá lograr metas y objetivos con la máxima eficiencia y el menor esfuerzo; además:

- Crear conciencia de responsabilidad universitaria

- Desarrollo organizacional y mejoramiento continuo

- Actuar con ética y valores morales

- Políticas racionales y aplicables

- Satisfacción en el trabajo

- Disciplina laboral

- Estabilidad emocional

- Ambiente laboral agradable

- Tecnología educativa actualizada

- Procesos educativos sistematizados

- Dedicación a la investigación, incentivada.

La sumatoria de estos factores garantizará una universidad acreditada nacional e internacionalmente. 


\section{Sistema de Gestión Universitaria de Calidad}

El sistema de gestión universitaria de calidad, tiene que estar enfocado, como una herramienta de mejoramiento continuo, basado en sus tareas académicas de formación profesional-moral del estudiante; la investigación universitaria; y la proyección social y extensión universitaria, para la satisfacción de su entorno principal conformado por: el estudiante, el padre de familia, la empresa, el Estado y/o la sociedad en su totalidad.

Dentro de este esquema, el SISGUC, en lo académico y administrativo; necesariamente, tiene que partir de una Política de Gestión Universitaria de Calidad, de la Alta Dirección, como un lineamiento de acción aplicable y a cumplirse en su cabalidad; de lo contrario, todo esfuerzo será vano.

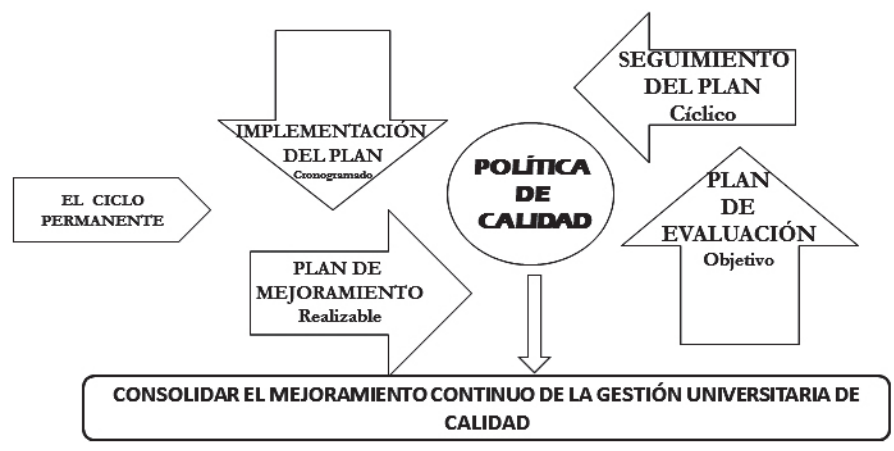

Un SISGUC se Consolida, bajo Responsabilidad, en la Alta Dirección, con Controles Cíclicos, a través de los mandos medios.

$\checkmark$ Reporte cíclico de auditoría interna: Académico y administrativo

$\checkmark$ Informes de auditoría objetivas y publicado

$\checkmark$ Acciones preventivas en lo económico, académico y administrativo

$\checkmark$ Acciones correctivas y motivacionales en lo académico

$\checkmark$ Acciones de atención a quejas, reclamos, sugerencias y proyectos

$\checkmark$ Incentivos por mejoramiento académico - administrativo

$\checkmark$ Cumplimiento irrestricto del estatuto y la Ley.

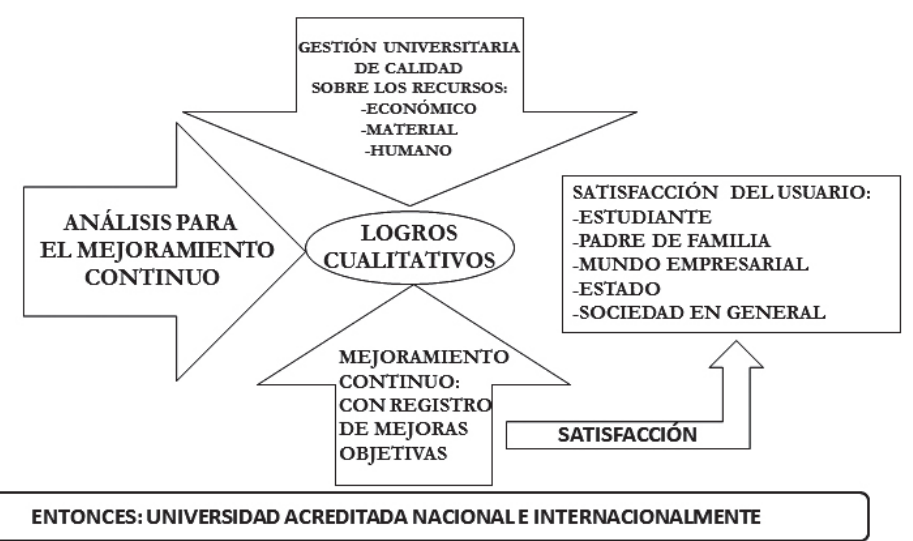

